\title{
Produção de trabalhos científicos em eventos nacionais da área de ciência da informação
}

\author{
The production of scientific research in national \\ events in the field of information science
}

Aline Elis ARBOIT'
Leilah Santiago BUFREM²

\section{Resumo}

Analisa diacronicamente a produção de trabalhos apresentados nos principais eventos nacionais no campo da Ciência da Informação. Recorre ao método cientométrico, levando em consideração a questão social e histórica do desenvolvimento do campo no País, nas etapas de levantamento, análise e interpretação dos dados. Como fonte de informação utiliza a Base de Dados de Literatura Cinzenta, na qual é cadastrada e indexada grande parte das comunicações apresentadas nos eventos. Representa graficamente e analisa a quantidade de trabalhos apresentados em relação às temáticas centrais de cada edição dos eventos selecionados, cobrindo o período entre 1954 e 2008. Relaciona os índices obtidos em cada período com o contexto histórico e político estabelecido no país, bem como o contexto relacionado ao desenvolvimento cognitivo da Ciência da Informação.

Palavras-chave: Ciência da Informação. Cientometria. Eventos científicos.

\begin{abstract}
This article performs a diachronic analysis of the research works presented in the main events in the field of Information Science in Brazil. The research resorts to a scientometric method, encompassing, in the stages of survey, analysis and interpretation of the gathered data, both the social and historical environments of the development of this field in the country. It uses, as its source of information, the Grey Literature Database, in which a large part of the communications presented in events, is registered and indexed. It represents in graphical format and analyses the number of works presented in relation to the main themes of each episode of the selected events, between 1954 and 2008 . It relates the indices obtained in each period to the historical and political context of the country, as well as to the context relating to the cognitive development of Information Science.
\end{abstract}

Keywords: Information science. Scientometry. Scientific events.

\section{Introdução}

Os eventos científicos são considerados meios mais informais e, com efeito, mais ágeis na transmissão e troca do conhecimento científico. Diferentemente dos meios convencionais de comunicação, tais como livros e periódicos, grande parte da informação é transferida oralmente, estimulando o debate instantâneo dos espe-

\footnotetext{
- Mestre, Tribunal de Contas do Estado do Paraná, Coordenadoria de Jurisprudência e Biblioteca. Praça Nossa Senhora da Salete, s/n., Centro Cívico, 80530-910, Curitiba, PR, Brasil. Correspondência para/Correspondence to: A.E. ARBOIT. E-mail: <aarboit@yahoo.com.br>.

2 Professora Doutora, Universidade Federal do Paraná, Programa de Pós-Graduação em Ciência, Gestão e Tecnologia da Informação e do Programa de Pós-Graduação em Educação. Curitiba, PR, Brasil.

Recebido em 21/12/2010, reapresentado em 22/3/2011 e aceito para publicação em 4/8/2011.
} 
cialistas interessados no tema. No entanto, antes de se tornarem públicos os trabalhos submetidos ao evento passam por avaliação rigorosa do comitê científico, comumente constituído por especialistas do campo. Esse processo de avaliação é similar ao dos artigos de periódicos, apesar da publicação em periódicos científicos ser, em geral, mais valorizada. Os eventos permitem também o contato informal entre os pesquisadores que atuam na mesma área do conhecimento. Assim, congregam pessoas com interesse comum, estimulam a troca e compartilhamento de conhecimento e a criação de novas parcerias ou grupos, uma vez que a troca de informações e conhecimento se dá de forma mais dinâmica do que os outros meios de comunicação científica, apesar do seu caráter menos formal.

No entanto, de acordo com Campello e Campos (1993), a importância dada aos eventos varia de campo para campo. Na Informática, por exemplo, os eventos figuram como o veículo mais importante de comunicação científica, pois neste campo o desenvolvimento se dá mais rapidamente que os demais. Por outro lado, nas Ciências Humanas, os eventos não têm a mesma importância que os livros e os artigos de periódicos, porque como este tipo de ciência requer longos períodos de reflexão, a obsolescência do conhecimento nestas áreas se dá mais lentamente.

Na Ciência da Informação (Cl) os eventos são considerados de grande valor cultural para o desenvolvimento da área, apesar de não ocuparem o mesmo status que os periódicos científicos, especialmente sob o olhar das agências de fomento. Neste sentido, Mueller (2008) observa que os diferentes campos do conhecimento privilegiam tipos de publicação diferentes como canais preferenciais para divulgação e validação do conhecimento que produzem. Segundo Mueller (2008), estudos mostram que as Ciências Naturais e Exatas dão preferência ao artigo científico, as Engenharias e Tecnologias preferem os encontros científicos e as Ciências Sociais se utilizam tanto de artigos quanto de livros e capítulos de livros. Logo, pode-se afirmar que a Cl, sendo considerada uma Ciência Social, também privilegia a publicação de artigos e capítulos de livros.

\section{Métodos}

Importantes contribuições para que se efetive e aperfeiçoe o processo de comunicação científica, os eventos científicos do campo da Cl são analisados neste artigo a partir de sua evolução quantitativa, considerando-se os mais abrangentes em nível nacional: o Congresso Brasileiro de Biblioteconomia e Documentação (CBBD), o Seminário Nacional das Bibliotecas Universitárias (SNBU) e o Encontro Nacional da Associação Nacional de Pós-Graduação em Ciência da Informação e Biblioteconomia (Enancib).

Os eventos foram representados quanto à regularidade e relação do número de trabalhos apresentados com a temática principal de cada edição, bem como a influência do contexto histórico na escolha destas temáticas.

Para coletar dados sobre estes eventos, recorreu-se à Base de Literatura Cinzenta (BLC), na qual é cadastrada e indexada grande parte das comunicações neles apresentadas. A BLC é um produto do subprojeto destinado ao eixo temático sobre a categoria da literatura cinzenta "Eventos", integrante do Núcleo de Pesquisa de Produção Científica, financiado pelo Conselho Nacional de Desenvolvimento Científico e Tecnológico (CNPq) e vinculado à Escola de Comunicação e Artes (ECA) da Universidade de São Paulo (USP) (Universidade de São Paulo, 2009). Considerando que esta base se encontra em processo de construção, foram consultados também acervos de bibliotecas universitárias e particulares, para complementar os dados.

\section{Resultados e Discussão}

O CBBD é o evento mais tradicional, principalmente da área de Biblioteconomia. No entanto, ao analisar as temáticas principais das 22 edições já ocorridas do evento, descritas no Anexo, verifica-se que, com o passar do tempo, o tema "Informação" tem estado mais presente do que o tema "Biblioteca". Logo, o CBBD, apesar do nome, pode ser assim considerado um dos principais eventos de $\mathrm{Cl}$.

Na Figura 1, observa-se que a quantidade de trabalhos nas três primeiras edições do evento, 1954, 1959 e 1961, praticamente se manteve, ao passo que, nos eventos de 1963 e 1967, registra-se um tímido crescimento. Ao confrontar a Figura 1 com o Anexo, verifica-se que a temática geral destas cinco primeiras edições do evento gira em torno da prática biblioteconômica, embora nas 
duas últimas seja dada mais ênfase ao papel social da biblioteca.

Ainda de acordo a Figura 1, no evento de 1971, verifica-se que o número de apresentações retorna aos índices apresentados nos três primeiros eventos, embora em 1973 cresça novamente. Em 1975 registra-se queda em relação a 1973. No evento de 1977 são apresentados 182 trabalhos, mais que o triplo da edição anterior. Retomando o Anexo, é possível observar que em 1971 a temática se debruça principalmente em aspectos operacionais do campo, enquanto em 1973, a temática privilegia aspectos relacionados aos programas de desenvolvimento científico e tecnológico e a informação. Já em 1975, retomam-se às questões sociais das bibliotecas e sua contribuição para educação. O evento de 1977 retoma a temática de 1973 sobre o Sistema de Informação para o Desenvolvimento, mas também abor- dando questões como a educação do profissional bibliotecário e o papel dos movimentos associativos no campo.

Aqui se faz necessário lembrar os resultados detectados no trabalho de Bufrem (1997) acerca das tendências metodológicas e temáticas das teses de dissertações do Programa de Pós-Graduação em Cl do Instituto Brasileiro de Informação em Ciência e Tecnologia (IBICT). Segundo a autora, na década de 1970 as pesquisas eram desenvolvidas praticamente em torno de questões pragmáticas e operacionais relacionas ao campo ${ }^{3}$. Logo, verifica-se que a temática do CBBD nesta época acompanha as pesquisas desenvolvidas no mestrado em Cl do Ibict.

As temáticas abordadas em 1977 convergem com o fortalecimento do programa nacional em Ciência e Tecnologia (C\&T) representado pelo Sistema de Infor-

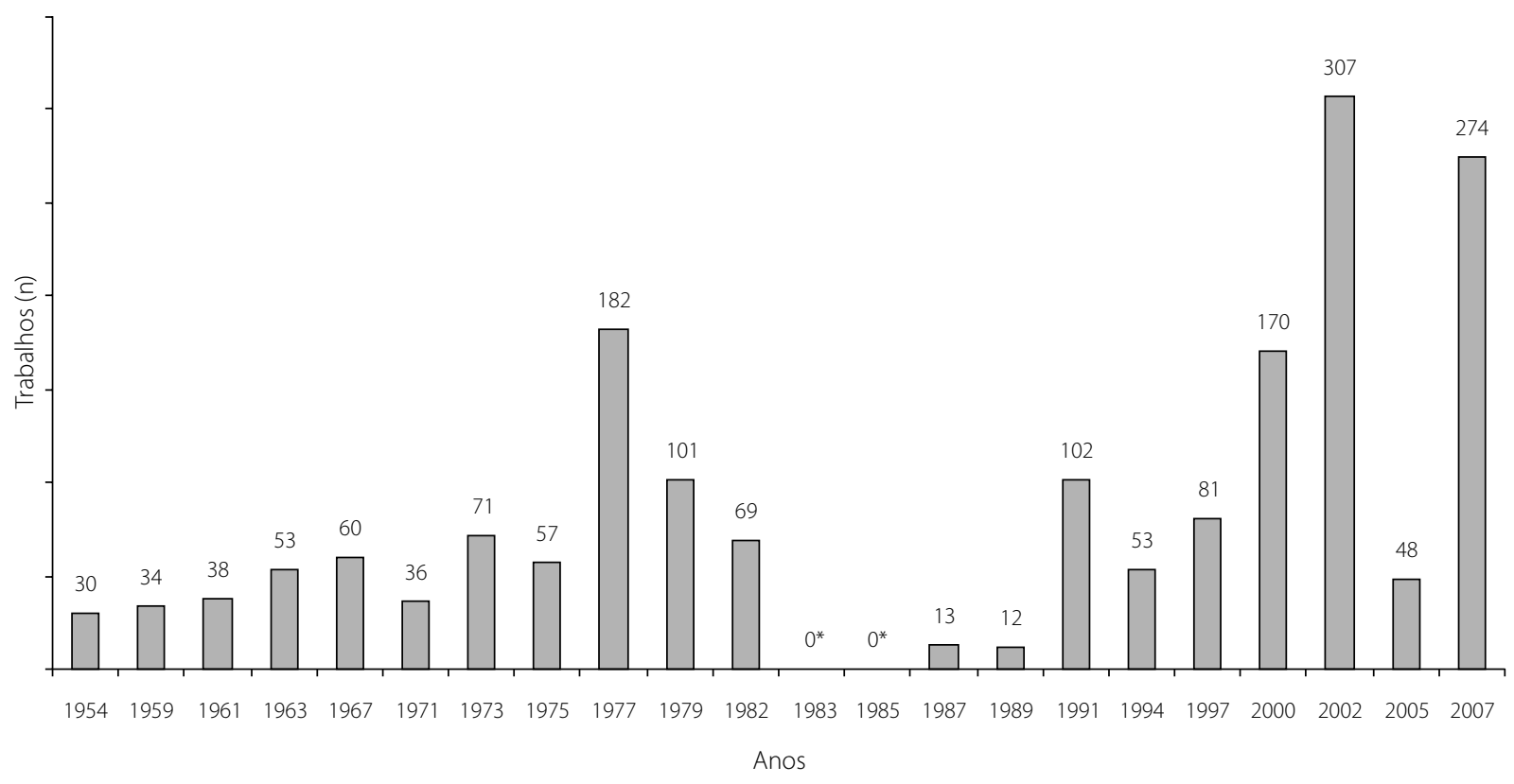

Figura 1. Quantidade de trabalhos apresentados no Congresso Brasileiro de Biblioteconomia e Documentação a cada edição do evento (1954-2007).

Fonte: Base de Literatura Cinzenta e nos anais dos eventos (2009).

Nota: " Sobre os eventos de 1983 e 1985 não foram encontradas informações acerca da quantidade de trabalhos apresentados.

\footnotetext{
3 Segundo classificação Bufren, no período de 1972 a 1983 os temas sobre os quais se produzia eram respectivamente: "Padrões e estruturas de informação registrada", "Planejamento e/ou gerenciamento de unidades ou sistemas de informação," "Processamento e recuperação da informação" e "Uso, usuários e transferência de informação". Ademais, a lista de autores citados nos trabalhos revela o predomínio de linhas quantitativas como Bradford, Solla Price, Lancaster, Saracevic, Goffman, Braga, Brookes, Kremer, Zipf e Bailey (Bufrem, 1997, p.71).
} 
mação para o Desenvolvimento Nacional. Para ilustrar, no ano anterior, o IBBD passou a se chamar IBICT, também em função desta demanda governamental. Daí é possível explicar o aumento considerável de trabalhos apresentados neste evento. De acordo com Barreto (2009), as inovações tecnológicas, bem como o estímulo da Organização das Nações Unidas para a Educação, a Ciência e a Cultura (UNESCO) e da Fundação Getúlio Vargas (FGV), foram os principais responsáveis por esta mudança de orientação do IBICT, que passou a ter como objetivo"apoiar o Sistema Nacional de Desenvolvimento Científico e Tecnológico, por meio do acesso às informações em C\&T e com a intenção de desenvolver e implantar uma rede de informação no País" (Barreto, 2009, p.10).

Nos eventos seguintes, de 1979 e 1982, o número de apresentações cai significativamente. Sobre os eventos de 1983 e 1985 não foram encontradas informações acerca da quantidade de trabalhos apresentados. Em 1987 e 1989 registra-se uma quantidade inexpressiva de trabalhos, embora em 1991 tal quantidade aumente de forma substancial. De acordo com o Anexo, a edição de 1979 se preocupa em fazer uma avaliação acerca das perspectivas do bibliotecário e a de 1982 retoma a questão da educação do profissional. Em 1983 é discutida a informação no âmbito da C\&T e o desenvolvimento nacional e em 1985 são discutidos temas como a informação e a sociedade, hábito de leitura e a questão profissional. A democratização da informação é tema da edição de 1987, enquanto o gerenciamento da informação é o tema de 1989. Em 1991 o tema geral do evento é o papel da biblioteca no desenvolvimento econômico e social.

No evento de 1994 a quantidade de trabalhos cai pela metade em relação a 1991, ao passo que em 1997 e 2000 o número de trabalhos cresce até atingir o ápice de 307 trabalhos em 2002. Porém em 2005, o índice cai substancialmente para 48, mas já na edição seguinte, em 2007, o número se eleva para 274. A temática abordada em 1994 é a transferência de informação; em 1997 é a questão dos impactos da globalização no campo; em 2000, informação e cidadania e o papel do profissional de informação; em 2002, a dimensão humana, política e econômica da informação; em 2005, a leitura e o papel das bibliotecas para cidadania; e em 2007, a questão do acesso à informação e o advento das bibliotecas digitais.
Do exposto, verifica-se que os eventos em que a temática gira em torno principalmente da leitura e das bibliotecas, como em 2005, a quantidade de trabalhos cai, o que não ocorre com eventos cujo tema principal seja a informação e as bibliotecas digitais, como em 2007. Deste modo, verifica-se que questões de cunho social, consideradas mais tradicionais, como é o caso da leitura, não são tão valorizadas no campo quanto às questões sociais emergentes sobre acesso e transferência de informação e cidadania. Tal tendência pode ser decorrente da assimilação do paradigma social proposto por Capurro (2003) ou abordagem social proposta por Wersig (1993), que vêm sentido na informação de acordo com o contexto coletivo que a rodeia.

Voltando-se para o Seminário Nacional de Bibliotecas Universitárias (SNBU) evento que, embora se destine principalmente a questões específicas das bibliotecas universitárias, também é considerado abrangente, uma vez que aborda temas que podem ser aplicados a outros ambientes informacionais. Isso pode ser percebido por meio do Quadro 1, que traz a temática principal de cada edição do evento, local de realização e ano. Partindo-se do confronto entre os dados levantados no Quadro 1 e no Figura 2, é possível examinar como ocorre a evolução temática e quantitativa do evento em questão.

De acordo com a trajetória obtida na Figura 2, observa-se que de 1978 a 1996 não houve um aumento considerável no número de trabalhos apresentados. No primeiro ano do evento foram apresentados 29 trabalhos. Três anos após, na edição de 1981, a quantidade de trabalhos praticamente dobra para 64. Já em 1985, observa-se uma queda em relação a 1981 (21 trabalhos) e, em 1987, a Figura 2 registra uma tímida elevação de 38 trabalhos. Em 1994 o número praticamente se mantém com 41; em 1994, aumenta para 63, mas logo em 1996, o número cai novamente para 45. Sobre as edições de 1983 e 1989, como não foram encontrados os anais destes eventos, não foi possível quantificar os trabalhos neles apresentados.

No Quadro 1, as temáticas dos eventos ocorridos entre os anos de 1978 e 1996 privilegiam temas sobre a biblioteca universitária no contexto de desenvolvimento e da pesquisa nacional, sobre gerenciamento e prestação de serviços, sobre usuários e sobre a biblioteca universitária na sociedade da informação. Os temas abordados 


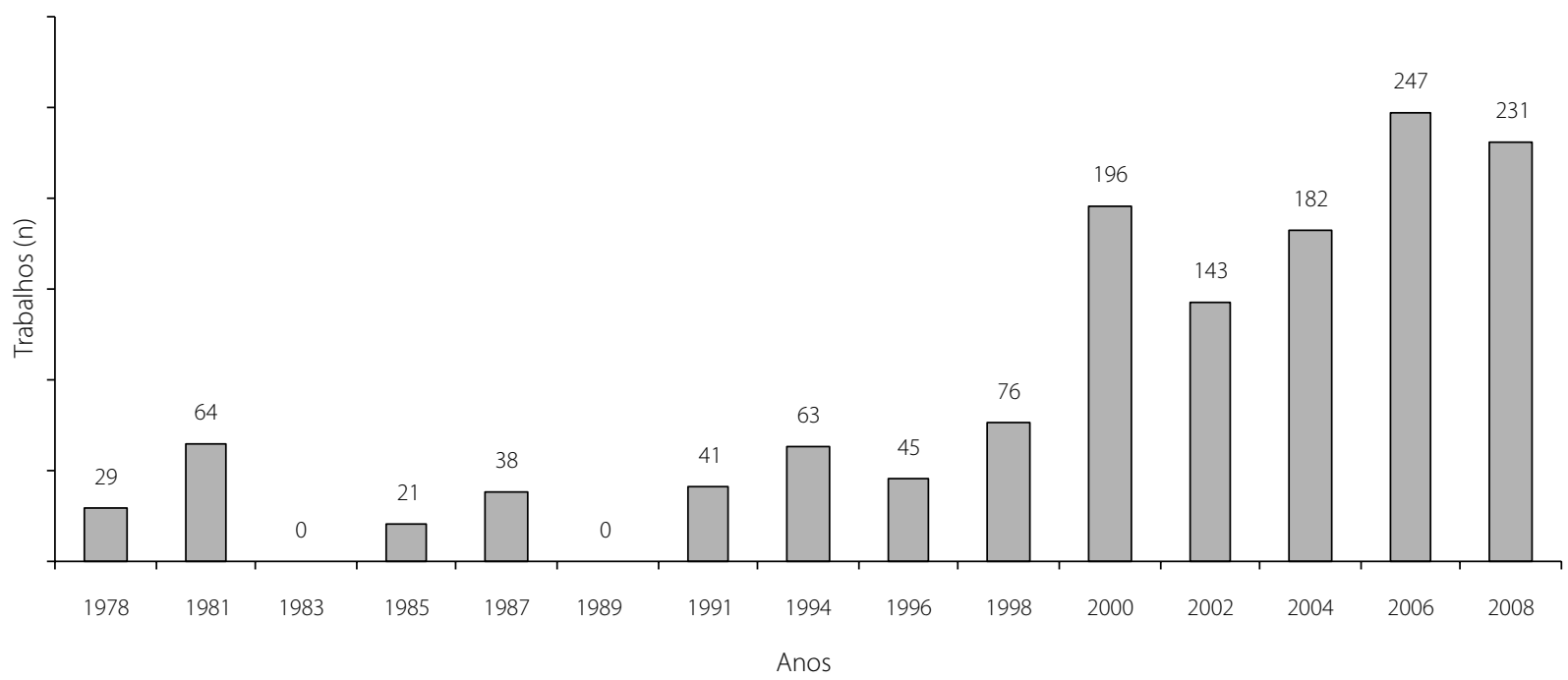

Figura 2. Quantidade de trabalhos apresentados no Sistema nacional de Bibliotecas Universitárias a cada edição do evento, $1978-2008$.

Fonte: Base de Literatura Cinzenta e nos anais dos eventos (2009).

pelo evento neste período convergem de modo geral com os temas escolhidos pelo CBBD que refletem, por sua vez, o panorama nacional das pesquisas em $\mathrm{Cl}$ sobre o desenvolvimento tecnológico e científico no Brasil. Além disso, o enfoque dado ao gerenciamento de unidades/sistemas de informação e à automação de bibliotecas, como já visto, é reflexo do considerável índice de pesquisas realizadas na pós-graduação em $\mathrm{Cl}$ sobre o assunto e dos debates teóricos que ocorriam na área. Para ilustrar, na década de 1980, Saracevic (1996) apresentau um novo conceito de $\mathrm{Cl}$ voltado para área de Administração e Tecnologia da Informação (TI), no qual ele vincula o campo ao social, institucional ou individual do uso e das necessidades de informação, cujo tratamento ocorre com apoio essencial das tecnologias modernas de informação.

O período entre 1998 e 2008 (Figura 2) caracteriza-se por um crescimento expressivo na quantidade de trabalhos. Entre 1998 e 2000 registra-se o maior índice de crescimento da produção, ou seja, o número de trabalhos para de 76 para 196. Entretanto, em 2002 há uma queda para 143. Na edição seguinte, de 2004, o índice aumenta para 184; em 2006 para 247, em 2008 a quantidade praticamente se mantém com 231 trabalhos.

Os temas principais das edições do SNBU de 1998 a 2008 tratam de modo geral das perspectivas da biblioteca universitária frente às mudanças tecnológicas, à sociedade da informação e à sociedade do conhecimento.
O crescimento constante da quantidade de trabalhos apresentados no período detectado na Figura 2 demonstra a preocupação do campo em relação ao contexto social da informação e do conhecimento e as demandas de inovação e estratégia para que as bibliotecas universitárias acompanhem a tendência expressa pelos teóricos do campo, especialmente sobre o paradigma/abordagem social da $\mathrm{Cl}$.

Em relação ao Enancib, principal evento de pós-graduação em Cl do Brasil, verifica-se que a análise temática deve ser realizada de maneira diversa dos eventos anteriores. Ou seja, embora cada edição do Enancib tenha uma temática principal, com exceção das três primeiras edições de 1994 a 1997, os temas dos trabalhos se debruçam nos eixos temáticos dos grupos de trabalho. 0 Quadro 2 traz informações sobre os grupos de trabalho e temáticas principais de cada edição do evento, além das informações como local e data. Observa-se que praticamente a cada edição a nomenclatura dos grupos de trabalho modifica-se, como aponta Barreto (2009). Isto é, para o autor a transitoriedade dos nomes e conteúdos abordados por cada grupo revela tentativa de atender mais a interesses momentâneos do que a busca de uma fundamentação teórica sólida para o campo.

A Figura 3 traz a evolução da quantidade de trabalhos edição do Enancib, entre os anos de 1994 e 2000. Observa-se que entre 1994 e 2000, o número de trabalhos cresce constantemente, praticamente dobrando a cada 
Quadro 1. Temas gerais de cada edição do SNBU (1978-2008).

\begin{tabular}{|c|c|c|}
\hline Edições e temáticas principais do evento & Local & Ano \\
\hline $\begin{array}{l}\text { I SNBU - A biblioteca como suporte do ensino e da pesquisa no } \\
\text { desenvolvimento nacional }\end{array}$ & Universidade Federal Fluminense (UFF), Niterói & 1978 \\
\hline $\begin{array}{l}\text { ॥ SNBU - Avaliação do desempenho da biblioteca universitária no } \\
\text { Brasil }\end{array}$ & $\begin{array}{l}\text { Coordenação de Aperfeiçoamento de Pessoal de Nível } \\
\text { Superior (CAPES), Brasília }\end{array}$ & 1981 \\
\hline III SNBU - Mecanismo de administração de bibliotecas universitárias & Universidade Federal do Rio Grande do Norte (UFRN), Natal & 1983 \\
\hline IV SNBU - Bibliotecas universitárias: usuários e serviços & Universidade de Campinas (Unicamp), Campinas & 1985 \\
\hline V SNBU - Plano nacional de bibliotecas universitárias & $\begin{array}{l}\text { Universidade Federal do Rio Grande do Sul (UFRGS), Porto } \\
\text { Alegre }\end{array}$ & 1987 \\
\hline VI SNBU - Automação de bibliotecas e serviços aos usuários & Universidade Federal do Pará (UFPA), Belém & 1989 \\
\hline $\begin{array}{l}\text { VII SNBU - Padrões nacionais para planejamento e avaliação em } \\
\text { bibliotecas universitárias }\end{array}$ & Universidade Federal do Rio de Janeiro (UFRJ), Rio de Janeiro & 1991 \\
\hline VIII SNBU - Integração e compartilhamento & Universidade de Campinas (Unicamp), Campinas & 1994 \\
\hline IX SNBU - A biblioteca universitária e a sociedade da informação & $\begin{array}{l}\text { Universidade Federal do Paraná (UFPR) e Pontifícia Univer- } \\
\text { sidade Católica do Paraná (PUC-PR), Curitiba }\end{array}$ & 1996 \\
\hline $\begin{array}{l}\text { X SNBU - Gestão de bibliotecas universitárias: estratégias para um } \\
\text { novo tempo. }\end{array}$ & $\begin{array}{l}\text { Universidade Federal do Ceará (UFC), Biblioteca Universitária; } \\
\text { Universidade de Fortaleza (UNIFOR), Biblioteca e Associação } \\
\text { dos Bibliotecários do Ceará (ABC), Fortaleza }\end{array}$ & 1998 \\
\hline XI SNBU - A biblioteca universitária do Século XXI & $\begin{array}{l}\text { Universidade Federal de Santa Catarina (UFSC). Biblioteca } \\
\text { Universitária, Departamento De Ciência Da Informação da } \\
\text { UFSC, colaboração da Associação Catarinense Das Fundações } \\
\text { Educacionais (ACAFE), Florianópolis }\end{array}$ & 2000 \\
\hline $\begin{array}{l}\text { XII SNBU - Bibliotecas universitárias: espaços de (r)evolução do } \\
\text { conhecimento e da informação }\end{array}$ & Universidade Federal de Pernambuco (UFPE), Recife & 2002 \\
\hline $\begin{array}{l}\text { XIII SNBU - Bibliotecas universitárias: (re)dimensão de bibliotecas } \\
\text { universitárias: da gestão estratégica à inclusão social. }\end{array}$ & Universidade Federal do Rio Grande do Norte (UFRN), Natal & 2004 \\
\hline $\begin{array}{l}\text { XIV SNBU - Acesso livre à informação científica e bibliotecas univer- } \\
\text { sitárias }\end{array}$ & Universidade Federal da Bahia (UFBA), Salvador & 2006 \\
\hline $\begin{array}{l}\text { XV SNBU - Empreendedorismo e inovação: desafios da biblioteca } \\
\text { universitária }\end{array}$ & CRUESP Bibliotecas (Unicamp, UNESP, USP) & 2008 \\
\hline
\end{tabular}

SNBU: Seminário Nacional de Bibliotecas Universitárias.

Fonte: Universidade Federal do Ceará (2010).

edição do evento. No entanto, verifica-se que a periodicidade do Enancib caracteriza-se pela irregularidade, pois desde o primeiro evento o intervalo entre cada edição já variou de um ano para dois e ainda para três, e de 2005 em diante para um novamente. Mesmo com três anos de intervalo, entre 2000 e 2003, a quantidade de trabalhos cai quase pela metade (de 250 para 139). Na edição seguinte, em 2005, o número se mantém (125), ao passo que em 2006 sofre uma pequena queda (110), já na edição de 2007 sofre um pequeno aumento (144).

Ao interpretar os dados da Figura 3 à luz do Quadro 2, observa-se que, no período de 1994 a 2000, ocorreu a maior parte das mudanças, não só na nomenclatura, mas na criação de novos grupos. Entretanto, entre 2003 e 2005 o nome e a ordem de praticamente todos os grupos se modificam, e o grupo destinado ao tema tecnologia da informação foi excluído. Isso pode ser explicado pela queda de quase 50\% dos trabalhos entre 2000 e 2003, talvez motivo pelo qual tenha ocorrido a reestruturação temática dos grupos em 2005, que permanece, com algumas modificações, até 2007. Diante disso, é possível perceber uma mudança de orientação da Ancib no tocante ao novo enfoque dado aos estudos teóricos, especialmente a questões históricas e epistemológicas da Cl, bem como a questões políticas, éticas e econômicas atrelada ao campo. Isso não significa, no entanto, que os 
Quadro 2. Temas gerais e grupos de trabalho de cada edição Enancib (1994-2007).

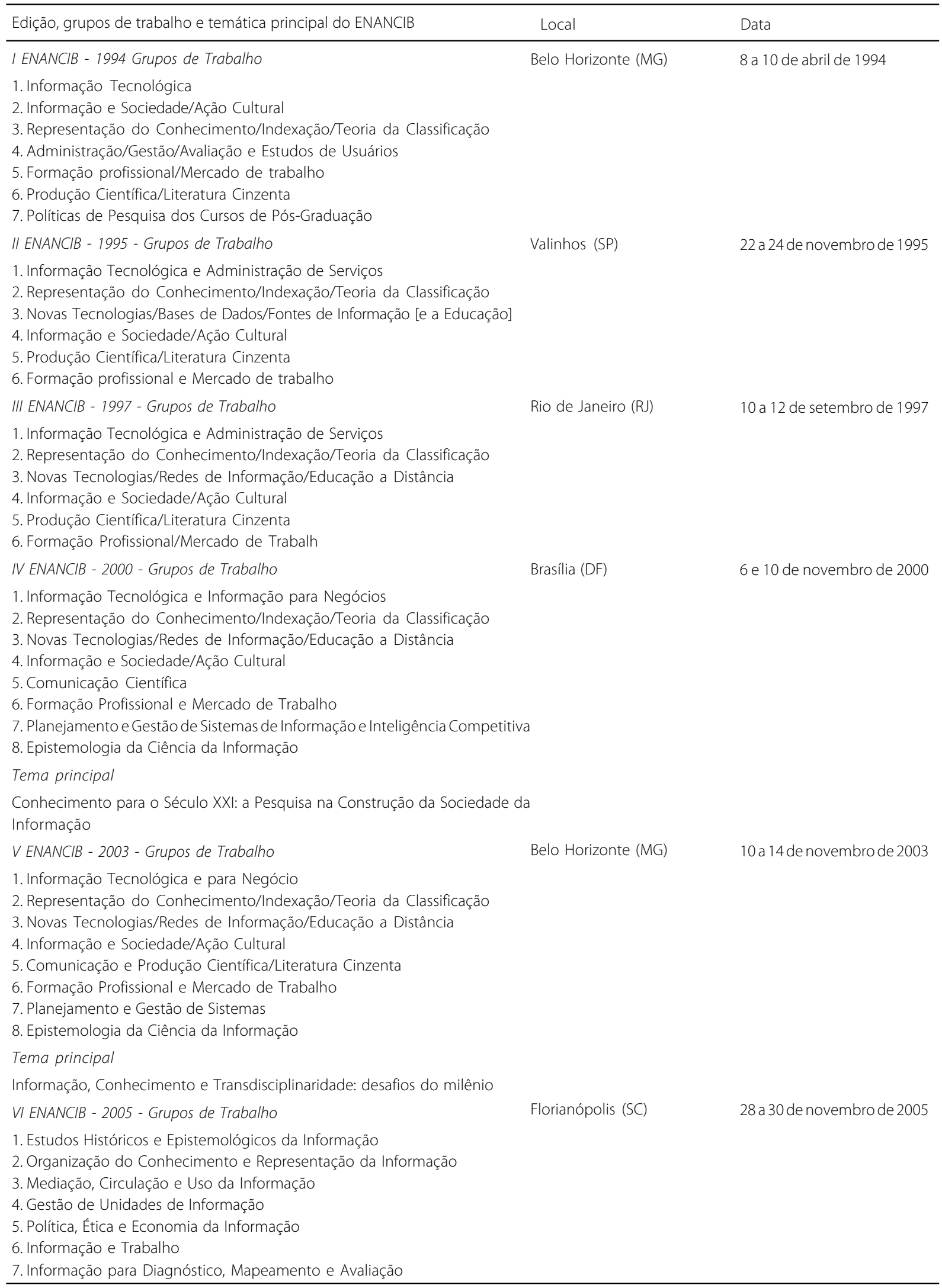


Quadro 2. Temas gerais e grupos de trabalho de cada edição Enancib (1994-2007).

Conclusão

\begin{tabular}{|c|c|c|}
\hline Edição, grupos de trabalho e temática principal do ENANCIB & Local & Data \\
\hline \multicolumn{3}{|l|}{ Tema principal } \\
\hline \multicolumn{3}{|l|}{ A política científica e os desafios da sociedade da informação } \\
\hline VII ENANCIB - 2006 - Grupos de Trabalho & Marília (SP) & 19 e 22 de novembro de 2006 \\
\hline $\begin{array}{l}\text { 1. Estudos Históricos e Epistemológicos da Informação } \\
\text { 2. Organização do Conhecimento e Representação da Inform } \\
\text { 3. Mediação, Circulação e Uso da Informação } \\
\text { 4. Gestão de Unidades de Informação } \\
\text { 5. Política, Ética e Economia da Informação } \\
\text { 6. Informação e Trabalho } \\
\text { 7. Informação para Diagnóstico, Mapeamento e Avaliação }\end{array}$ & & \\
\hline \multicolumn{3}{|l|}{ Tema principal } \\
\hline \multicolumn{3}{|c|}{$\begin{array}{l}\text { A dimensão epistemológica da Ciência da Informação e suas interfaces técnicas, } \\
\text { políticas e institucionais nos processos de produção, acesso e disseminação da } \\
\text { informação }\end{array}$} \\
\hline VIII ENANCIB - 2007 - Grupos de Trabalho & Salvador (BA) & 28 a 31 de outubro de 2007 \\
\hline $\begin{array}{l}\text { 1. Estudos Históricos e Epistemológicos da Informação } \\
\text { 2. Organização e Representação do Conhecimento } \\
\text { 3. Mediação, Circulação e Uso da Informação } \\
\text { 4. Gestão de Unidades de Informação } \\
\text { 5. Política e Economia da Informação } \\
\text { 6. Informação, Educação e Trabalho } \\
\text { 7. Produção e Comunicação da Informação em CT\&l }\end{array}$ & & \\
\hline \multicolumn{3}{|l|}{ Tema principal } \\
\hline $\begin{array}{l}\text { Promovendo a inserção internacional da pesquisa brasileir } \\
\text { Informação }\end{array}$ & & \\
\hline
\end{tabular}

ENANCIB: Encontro Nacional de Pesquisa em Ciência da Informação.

Fonte: Associação Nacional de Pesquisa e Pós-Graduação em Ciência da Informação (2009a).

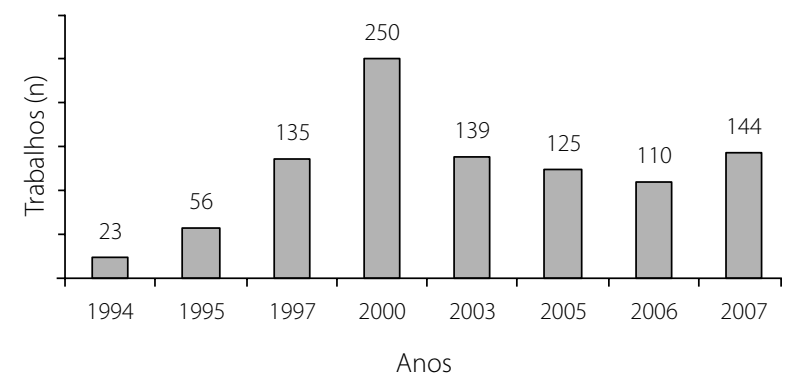

Figura 3. Quantidade de trabalhos apresentados no Enancib a cada edição do evento, 1994-2007.
Fonte:As autoras, com base em dados levantados na Base de Literatura Cinzenta enos anais dos eventos (2009).

estudos mais pragmáticos tenham perdido sua importância no campo, apesar da exclusão momentânea do grupo específico de tecnologias da informação.

\section{Considerações Finais}

A análise dos eventos ocorridos em Cl no país partiu do confronto entre as temáticas principais eleitas e a quantidade de trabalhos apresentados em cada edição. Foi possível confirmar o já exposto, especialmente no que diz respeito às organizações científicas sobre a indução das tendências temáticas de cunho técnico-operacional de pesquisa pelas agências nacionais de fomento. As tendências temáticas mais recentes têm se voltado à questão social da informação, com quantidade expressiva de trabalhos apresentados. No entanto, quando os temas são as bibliotecas tradicionais e a importância da leitura, a quantidade de trabalhos cai consideravelmente. Isso traz à baila contradições e divergências presentes no campo que, por sua vez, afetam o nível de instituciona- 
lização cognitiva e, consequentemente, o nível de institucionalização social.

Do exposto também se verifica que, embora este tipo de canal de comunicação científica não seja o mais valorizado na área pelas agências de fomento, ele constitui uma fase intermediária no processo de legitimação do conhecimento científico. Ou seja, os eventos refletem a tendência das pesquisas baseada nos anseios e discussões da comunidade científica durante o evento. Deste modo, constituem-se em uma valiosa fonte de informação para a realização de estudos retrospectivos da $\mathrm{Cl}$.

\section{Referências}

ASSOCIAÇÃO NACIONAL DE PESQUISA E PÓS-GRADUAÇÃO EM CIÊNCIA DA INFORMAÇÃO. Grupos de trabalho. Disponível em: <http://www.ancib.org.br/grupos-de-trabalho>. Acesso em: 15 ago. 2009a.

ASSOCIAÇÃO NACIONAL DE PESQUISA E PÓS-GRADUAÇÃO EM CIÊNCIA DA INFORMAÇÃO. Histórico do ENANCIB. Disponível em: <http://www.ancib.org.br/enancib/historicodo-enancib>. Acesso em: 15 ago. 2009b.

BARRETO, A. Olhar sobre os 20 anos da Associação Nacional de Pesquisa e Pós-graduação em Ciência da Informação (ANCIB). Perspectiva Brasileira em Ciência da Informação, v.2, n.1, p.3-28, 2009.

BUFREM, L.S. Ciência da informação e história: o caso do IBICT. Transinformação, v.9, n.1, p.58-79, 1997.

CAMPELLO, B.S.; CAMPOS, C.M. Fontes de informação especializada: características e utilização. Belo Horizonte: UFMG, 1993.

CAPURRO, R. Epistemologia e Ciência da informação. In: ENCONTRO NACIONAL DE PESQUISA EM CIÊNCIA DA INFORMAÇÃO, 5., 2003, Belo Horizonte. Anais... Belo Horizonte: Escola de Ciência da Informação da UFMG, 2003.
No levantamento de dados sobre os eventos, não foi possível ter acesso a alguns anais de determinadas edições, pois estes não foram encontrados disponíveis em nenhuma biblioteca consultada, e consequentemente, os trabalhos apresentados nestas edições não foram cadastrados na base BLC. A ausência dos anais dessas edições, embora afete os resultados da análise, não invalida o trabalho realizado. Esse fato é um alerta para a necessidade de preservação e organização desses anais, especialmente com vistas à recuperação por parte de pesquisadores, cujos estudos se orientem por enfoques históricos sobre a produção científica fundamentada nos eventos nacionais da área.

FEDERAÇÃO BRASILEIRA DE ASSOCIAÇÕES DE BIBLIOTECÁRIOS E CIENTISTAS DA INFORMAÇÃO. Relação de congressos promovidos. Disponível em: <http://www.febab.org. br/eventos_febab.htm>. Acesso em: 5 dez. 2009.

MUELLER, S.P.M. Literatura científica, comunicação científica e ciência da informação. In: TOUTAIN, L.M.B.B. Para entender a ciência da informação. Salvador: EDUFBA, 2008.

SARACEVIC, T. Ciência da informação: origem, evolução e relações. Perspectivas em Ciência da Informação, v.1, n.1, p.41-62, 1996.

UNIVERSIDADE FEDERAL DO CEARÁ. Relação de seminários promovidos. Disponível em: <http://www.biblioteca.ufc.br/ snbu.html>. Acesso em: 5 jan. 2010.

UNIVERSIDADE DE SÃO PAULO. Núcleo de pesquisa e produção científica. São Paulo: ECA/USP Disponível em: <http:// www.eca.usp.br/nucleos/pc/Recursos HumanosNPC19922 008.htm>. Acesso em: 15 ago. 2009.

WERSIG, G. Information science: the study of postmodern knowledge usage. Information Processing \& Management, v.29, n.2, p.229-239, 1993. 
ANEXO

TEMAS GERAIS DAS EDIÇÕES DO CBBD (1954-2007)

\begin{tabular}{|c|c|c|}
\hline CBBD & Local & Data \\
\hline \multicolumn{3}{|l|}{$11^{\circ} \mathrm{CBBD}$} \\
\hline $\begin{array}{l}\text { Situação atual do leitor brasileiro e Ensino Profissional } \\
\text { Processos técnicos } \\
\text { Bibliotecas públicas e bibliotecas infantis e de escolas primárias } \\
\text { Bibliotecas especializadas } \\
\text { Bibliografias, associações bibliotecárias e legislação profissional } \\
2^{\circ} \text { CBBD }\end{array}$ & Recife (PE) & 18 de julho de 1954 \\
\hline $\begin{array}{l}\text { Relações entre editores, livreiros e bibliotecários } \\
\text { Edifícios de bibliotecas, cooperação entre bibliotecários e arquitetos }\end{array}$ & Salvador (BA) & 1959 \\
\hline \multicolumn{3}{|l|}{$3^{\circ} \mathrm{CBBD}$} \\
\hline $\begin{array}{l}\text { Processos técnicos } \\
\text { Ensino de biblioteconomia e documentação } \\
\text { Profissão de bibliotecário-documentalista } \\
\text { Bibliografia e documentação: bibliotecas especializadas } \\
\text { Relações públicas e intercâmbio } \\
\text { Tipos de bibliotecas } \\
\text { Movimento associativo de classe }\end{array}$ & Curitiba (PR) & 8 a 15 de janeiro de 1961 \\
\hline $4^{\circ} \mathrm{CBBD}$ & & \\
\hline A educação através da biblioteca & Fortaleza (CE) & 7 a 14 de julho de 1963 \\
\hline $5^{\circ} \mathrm{CBBD}$ & & \\
\hline A biblioteca como fator de progresso & São Paulo (SP) & 8 a 5 de janeiro de 1967 \\
\hline $6^{\circ} \mathrm{CBBD}$ & & \\
\hline $\begin{array}{l}\text { Atividades profissionais } \\
\text { Planejamento e instalação }\end{array}$ & Belo Horizonte (MG) & 4 a 10 de julho de 1971 \\
\hline $7 \circ \mathrm{CBBD}$ & & \\
\hline $\begin{array}{l}\text { Sistema nacional de informações científicas e tecnológicas } \\
8^{\circ} \mathrm{CBBD}\end{array}$ & Belém (PA) & 29 de julho a 4 de agosto de 1973 \\
\hline $\begin{array}{l}\text { Responsabilidade social das bibliotecas no plano setorial da educação } \\
\text { go CBBD }\end{array}$ & Brasília (DF) & 20 a 25 de julho de 1975 \\
\hline $\begin{array}{l}\text { Integração do sistema de informação no desenvolvimento nacional } \\
\text { Educação bibliotecária } \\
\text { Movimento associativo }\end{array}$ & Porto Alegre (RS) & 3 a 8 de julho de 1977 \\
\hline $10^{\circ} \mathrm{CBBD}$ & & \\
\hline $\begin{array}{l}\text { Biblioteconomia brasileira: avaliação crítica e perspectivas } \\
11^{\circ} \mathrm{CBBD}\end{array}$ & Curitiba (PR) & 22 a 27 de julho de 1979 \\
\hline $\begin{array}{l}\text { Biblioteca e educação permanente } \\
12^{\circ} \mathrm{CBBD}\end{array}$ & João Pessoa (PB) & 17 a 22 de janeiro de 1982 \\
\hline $\begin{array}{l}\text { Informação e desenvolvimento nacional } \\
\text { Cultura, comunicação, ciência e tecnologia } \\
\text { O homem, o desenvolvimento }\end{array}$ & Camboriú (SC) & 23 a 29 de outubro de 1983 \\
\hline $13^{\circ} \mathrm{CBBD}$ & & \\
\hline $\begin{array}{l}\text { Informação no século XXI: lacunas presentes e perspectivas } \\
\text { Informação em uma sociedade democrática } \\
\text { Influência da problemática econômica no hábito de leitura do indivíduo } \\
\text { A questão profissional: a biblioteconomia e a interface com outras profissões }\end{array}$ & Vitória (ES) & 14 a 19 de julho de 1985 \\
\hline
\end{tabular}




\begin{tabular}{|c|c|c|}
\hline CBBD & Local & Data \\
\hline \multicolumn{3}{|l|}{$14^{\circ} \mathrm{CBBD}$} \\
\hline Biblioteca e democratização da informação & Recife (PE) & 20 a 25 de setembro de 1987 \\
\hline \multicolumn{3}{|l|}{$15^{\circ} \mathrm{CBBD}$} \\
\hline Gerenciamento da informação & Rio de Janeiro (RJ) & 27 de agosto a $1^{\circ}$ de setembro de \\
\hline $16^{\circ} C B B D$ & & 1989 \\
\hline Biblioteca e desenvolvimento econômico e social & Salvador (BA) & 22 a 27 de setembro de 1991 \\
\hline \multicolumn{3}{|l|}{$17^{\circ} \mathrm{CBBD}$} \\
\hline Transferência de informações no limiar do Ano 2000 & Belo Horizonte (MG) & 10 a 15 de abril de 1994 \\
\hline \multicolumn{3}{|l|}{$18^{\circ} \mathrm{CBBD}$} \\
\hline Os cenários da biblioteconomia em face da globalização da informação & São Luís (MA) & 20 a 25 de julho de 1997 \\
\hline \multicolumn{3}{|l|}{$19^{\circ} \mathrm{CBBD}$} \\
\hline Informação para a cidadania e o profissional da informação do novo milênio & Porto Alegre (RS) & 24 a 30 de setembro de 2000 \\
\hline \multicolumn{3}{|l|}{$20^{\circ} C B B D$} \\
\hline Dimensão humana, política e econômica da informação & Fortaleza (CE) & 23 a 28 de junho de 2002 \\
\hline \multicolumn{3}{|l|}{$21^{\circ} \mathrm{CBBD}$} \\
\hline Livro, leitura e bibliotecas: exercício da cidadania & Curitiba (PR) & 17 a 22 de julho de 2005 \\
\hline \multicolumn{3}{|l|}{$22^{\circ} \mathrm{CBBD}$} \\
\hline $\begin{array}{l}\text { Igualdade e diversidade no acesso à informação: da biblioteca tradicional à } \\
\text { biblioteca digital }\end{array}$ & Brasília (DF) & 8 a 11 de julho de 2007 \\
\hline
\end{tabular}

CBBD: Congresso Brasileiro de Biblioteconomia e Documentação.

Fonte: Federação Brasileira de Associações de Bibliotecários, Cientistas da Informação e Instituições (2009). 